\title{
Game-based Interactive Campaign using Motion-Sensing Technology
}

\author{
Alf Inge Wang ${ }^{1}$, Mari Hansen Asplem ${ }^{2}$, Mia Aasbakken ${ }^{3}$, and Letizia Jaccheri ${ }^{4}$ \\ Dept. of Computer and Information Science, \\ Norwegian University of Science and Technology, Trondheim, Norway \\ ${ }^{1}$ alfweidi.ntnu.no, ${ }^{2}$ mariashasa@gmail.com, \\ ${ }^{3} \mathrm{mia}$.aasbakken@gmail.com, ${ }^{4}$ letizia@idi.ntnu.no
}

\begin{abstract}
The article describes an evaluation of a prototype for doing gamebased interactive advertisement campaigns in crowded public spaces using motion-sensing technology. The prototype was developed using OpenNi, XNA and Kinect, in which people who pass by a large display would be reflected on a large screen in the form of a silhouette and automatically become a part of a game. The goal of the game is for the players to gather falling objects into a container using the body to direct the objects. The objects move around when the objects collide with the silhouette of the player. The graphical representation of the falling objects and the container can be changed to fit various advertisement purposes.

The game-based interactive campaign was tested at four different public locations, and was evaluated through observations and questionnaires. Our findings suggest that there is a potential for using motion control in game-based interactive campaigns in public settings. The game attracted a good amount of attention, and seemed to tempt the curiosity of passers-by. An observed trend was that participants were comfortable playing in public and got easily engaged. Children and adolescents in groups were by far the most active participants.
\end{abstract}

Keywords: Interactive advertisement campaigns, motion-sensing control, games, evaluation.

\section{Introduction}

As the world around us has become filled with more and more advertisements in the form of posters or public displays, people have learned to ignore such campaigns, and grabbing the attention of passers-by has become more challenging. LCD and plasma screens make it easy and cheap to create digital campaigns that can be replaced on the fly and opens an opportunity to incorporate interaction with the user, for example in the form of touch interfaces and body recognition. After over 20 years where graphical user interfaces have consisting of windows, icons, menus and pointing devices, there has been an increased interest in new interfaces based on multi-touch technology and gestures [1]. To control devices with body gestures have now become common for gaming systems like Nintendo Wii, PlayStation Move and Microsoft's Ki- 
nect, as well as smart-TVs and other smart devices. The casual game revolution introduced through smart phones, tables and game consoles like Nintendo Wii has made gaming common among both genders and among young and old [2]. By combining motion sensor technology and gaming, new types of interactive campaigns can be created that are far more engaging and enjoyable for the target audience. There has not been much research on using this type of technology for interactive campaigns, and it is an exciting area to explore. We are especially interested in how people perceive participating in interactive campaigns in public areas and the opportunities and limitations using such technology.

This paper presents an evaluation of a motion-controlled game that was developed to explore the opportunity of doing interactive advertisement campaigns using motion-sensing technology such as Microsoft Kinect. The testing of the game took place in a waterpark, a university campus, a movie theater, and a shopping mall. The goal of the evaluation was to investigate how people react to interactive campaigns using motion-control game technology in regards to joining the game, using body gestures for control, engagement, social aspects, and how the game affects the people's attitude towards a product.

\section{$2 \quad$ Material and Method}

This section presents the related work, the prototype of the motion-controlled interactive campaign game, and the research goal, questions and method.

\subsection{Related Work}

Gestural interaction is often referred to as "natural user interfaces", but they are not necessarily easy to learn or remember, and the same gesture can mean different things depending where you are [3]. However, despite some usability issues, gesture controls such as the Kinect in social games work very well as users quickly become immersed in the game [4]. Examples of using gesture and movement for various purposes are the Nautilus game where users can play in an interactive virtual space [5], and interactive art installations [6-8]. The immersion that motion-sensing technology can create along with the opportunity of public interactivity, makes this technology promising for running advertisement campaigns.

Public digital displays can be found all around us in public and semi-public spaces, and their main purpose is often advertising or displaying information [9]. A problem in the past has been the lack of interactivity they provide, but this is changing as (multi-) touch and motion-sensing technology becomes cheaper and more common. Many studies on interactive public displays have revealed an important problem: It is hard to get people to interact with them and a commonly cited reason is social embarrassment [10]. The main problem is transitioning from peripheral awareness (doing some activity away from the screen, but being peripherally aware of it) to focal awareness (focusing on the screen, watching it being used and talk about). One effect that help users move from peripheral to focal awareness occur when some people are standing 
around an installation and showing an interest in it, which leads to a progressive increase in the number of people in the immediate vicinity of the installation (the honey pot effect [10] ).

The Audience Funnel is a framework for investigating public displays by describing the different phases that make up the interaction process [11]. Between these phases there are thresholds that the user must either cross or that cause them to abort the interaction. The phases are 1) Passing by, 2) Viewing and Reacting, 3) Subtle Interaction, 4) Direct Interaction, 5) Multiple Interaction, and 6) Follow up Actions. The first four phases are attention-based while the last two focus on motivation.

Muller et al. describe some general models for attracting attention and these are Behavioral urgency, Bayesian surprise and Honey pot effect [12]. Behavioral urgency refers to the fact that certain things, such as the abrupt appearance of a new object, moving or looming stimuli, and some luminary contrast changes capture attention. Bayesian surprise refers to the difference between what someone expect and what she or he experienced in a situation, and adding elements of surprise that will be unexpected to the user can grab their attention. The honey pot effect is described above.

There is not a lot of research on understanding the motivating factors behind a user's activity, but the Magical Mirrors study identified a set of motivating factors [12] based on work by Malone [13]: Challenge and control (motivation based on user mastering something that has appropriate challenge level), Curiosity and exploration (solve or complete something that might be uncertain or incomplete), Choice (let users have control), Fantasy and metaphor (enrich the experience), and Collaboration (easier or more entertaining).

There have been some projects that have experimented with interactive displays or installations. One example is the Magical Mirrors where the installation consisted of four displays placed next to each other in a store front window in downtown Berlin [14]. The display showed a mirror image of the scene in front of it, and by using motion detection from a simple video, added optical effects to the image, such as ribbon following a moving hand or flowers growing from your hand. Another example was the CityWall installation in Helsinki [15], where a multi-touch screen in a store front window provided users with a timeline full of photos of the city downloaded from Flickr. Users could zoom in on the timeline and organize photos by moving, rotating and resizing them. A less public, but still collaborative interactive display is the BlueBoard device, intended for both personal and collaborative use in a work setting [16]. The BlueBoard is a plasma display with touch technology and an RFID reader some users can be identified by sweeping their card. It allows users to pull up personal information quickly and to collaborate on sketching ideas, sharing content and so on. Another example was Volvo's interactive commercial prior to screening the movie Ratatouille at twelve movie theaters across the UK where the audience controlled a Volvo through an obstacle course by holding their arm up into the air and moved their arms in the direction they wanted the car to go [17]. Another example of a commercial use of motion sensor technology is the virtual fitting room where an interactive display shows the user wearing various virtual clothes that move according to body movements detected by a Kinect motion detection device [18]. Our approach is dif- 
ferent from the described projects in being a game. Our motivation for choosing the game approach was to increase the immersion and engagement.

\subsection{The Prototype}

The game is a simple motion gesture game where the goal is to gather similar falling objects into a container of some sort. Once a certain number of objects have been collected, an advertisement campaign such as an image of an offer or a coupon code will be shown. The falling objects are controlled by moving the player's body so that the silhouette collides with them. Because the silhouette of a person appears on the screen as soon as they pass the sensor, she or he will immediately be a part of the game. The objects that fall down, the background, the container and the winning image can be easily replaced, thus changing the appearance of the game. The falling objects behave as physical objects and bounce of the silhouette, making it a challenge to get them into the container. Figure 1 shows a screenshot from a two-player game with two people in the background.

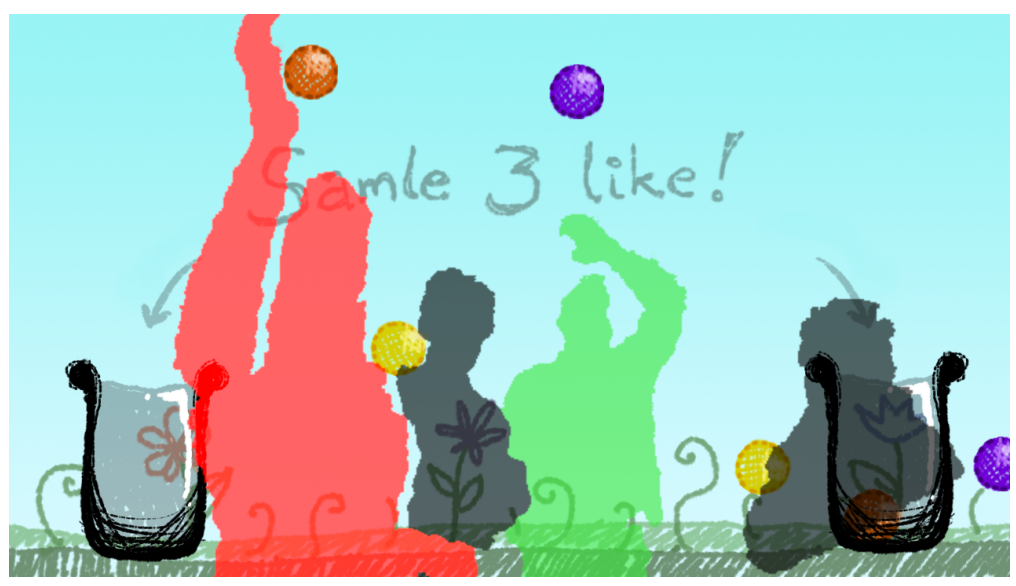

Fig. 1. Screenshot from a two-player game

The game prototype was made using XNA and utilizing the OpenNI (communication and management of motion sensor) and Farseer (physics engine) libraries. The OpenNi framework defines APIs developers can use for accessing Natural Interaction devices. It gives access to vision and audio sensors, and middleware that analyzes data from sensors. Examples of application areas for OpenNI are speech recognition, body motion tracking, and capturing body/hand gestures. The Farseer physics engine is an open source 2D physics engine made for the Microsoft .Net platform based on the BOX2D physics engine used for instance in the Angry Birds game from Rovio. Farseer uses four central concepts in order to simulate a moving body that can collide and interact with another body: World (a location of bodies, fixtures and constraints), Body (keeps track of a position in the world and is the backbone for fixtures), Shape (2D geometrical object in space), and Fixture (acts as glue and attaches the shape to the body and adds material properties like density, friction and restitution). 


\subsection{Research Goal, Questions and Method}

To provide a framework for conducting the research described in this article, the Goal Question Metric framework was used [19]. In the goal question metric approach we first define a research goal (conceptual level), then define a set of research questions (operational level), and finally describe a set of metrics to answer the defined research questions (quantitative level). The metrics used in our evaluation was a mixture of qualitative and quantitative data [20]. The research goal was defined as:

The purpose of this study was to understand and evaluate how users relate to motion-controlled applications in a public space.

The research goal was decomposed into the following research questions:

- RQ1: Are people comfortable becoming a part of and playing a motion-controlled game in a public space without explicitly giving permission?

- Metrics: Observation on site and questionnaire.

- RQ2: Which users are easiest to engage?

- Metrics: Observations.

- RQ3: Do people get engaged playing an interactive motion-controlled campaign?

- Metrics: Observations and questionnaire.

- RQ4: What roles do the social aspects play for participating in an interactive motion-controlled campaign?

- Metrics: Observations and questionnaire.

- RQ5: Does interactive motion-controlled campaign change the attitude of the people involved?

- Metrics: Observations and questionnaire.

Based on the research questions above, a questionnaire was designed. The observations were conducted by the two developers of the game. More details about the research design and questionnaire can be found in [21].

\section{Results}

This section presents the results from the evaluation of the prototype.

\subsection{Observations}

The interactive campaign was tested out in four different locations: The entrance area of a waterpark, at the a large corridor at the university campus with access to multiple lecture halls, cafeteria, offices and shops, the entrance of a candy store in a movie theater, and in an open space at a downtown shopping mall as shown in Figure 2. 


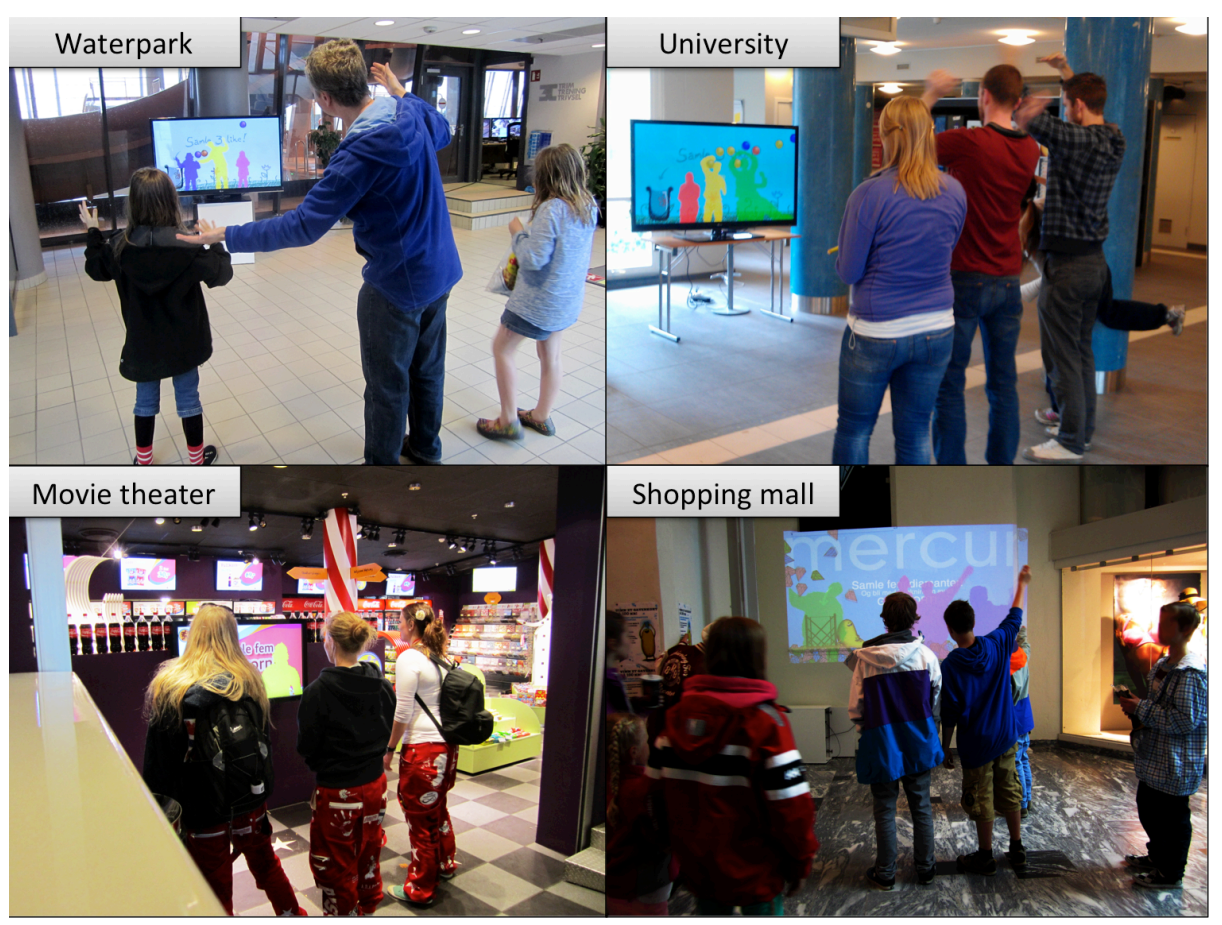

Fig. 2. Testing out the game-based interactive campaign

In the waterpark there was a relatively constant stream of people but not typically crowded in the entrance area, as people tend to spend a short time passing through the reception to enter the waterpark. Especially adults did not pay much attention to the stand and mostly focused on getting into the waterpark. The most eager groups were definitely elementary and middle school children. These children were drawn to the screen to try out the game. In some cases, the children encouraged their parents to try the game. Most of the children who played were very active, and they would run around, jump and yell, without seeming to be affected by the fact that the game was placed in a public space.

The testing of the interactive campaign at the university campus attracted a lot more participants. Most people who passed it did notice, and went from being passers-by in the audience funnel to viewing and reacting [12]. A fairly large portion of those who looked at the screen did not try to participate in the game. Some would walk by while doing a superfluous movement, such as waving an arm, without stopping, while others would exclaim: "Look, we're on TV" or "Is that us? No? Yes it's us!" Although the goal of the game is presented in the center of the screen, several people chose to have fun in the outer area of the screen. A small group of students danced and watched their silhouettes, while two other tried playing volleyball with the balls in the game. Some tried to grab a single ball with their hands, while others played around with capturing as many balls as possible between their arms. A large majority of those who stopped and started playing were in groups of two or more 
people, and most of them male. Mixed groups also stopped, but then most the female students played. Another way some experimented with the game was to use physical objects they were holding to control the game or even a backpack to hurl the balls around. When students won the game, the price was an advertisement for a lunch offering in the local store. The students were generally reluctant to the advertisement at the end of the game, but were positive to an alternative approach to advertisement.

The third location to test the interactive campaign was in front of the candy store in a movie theater. A problem in the movie theater common area was to be able to stand out, as there were many other screens and advertisement in the room. The graphics in the game for this location was falling popcorns and a popcorn container. At first very few noticed the interactive campaign, until a person standing in front of the screen accidentally started to move around popcorns. He got his friends over to the screen and then more people were drawn to the game (the honey pot effect). One surprise was that some thought the game was touch screen based and tried to control the game touching the screen.

The forth location was an open area in a shopping mall. The game was here tested both without and with a prize for winning the game. Offering a gift certificate as a prize greatly increased the amount of time people spent on playing and the amount of people who wanted to play. One observation at the mall was that the most frequent players were groups of teenage girls. Some boys that played did not try to win the game but rather used various body parts to move the balls around. Some men in their early twenties kicked balls to each other and had fun in this way. Another pattern in the mall was that those who stopped played for a very short period of time (about one minute). Another problem in the mall was that people standing behind the player would make it hard for the players to complete the task. The announcement of the prize made people more eager to figure out how to win the game and play longer and more. The prizewinners were drawn among the winners of the game.

\subsection{Empirical Results}

In the evaluation of the interactive campaign we had a total of 105 respondents, where 28 did not play the game and 77 played the game. $69 \%$ of the respondents were female vs. $31 \%$ male (similar gender distribution for those who played and those who did not play). The age distribution of the group is shown inn Figure 3.

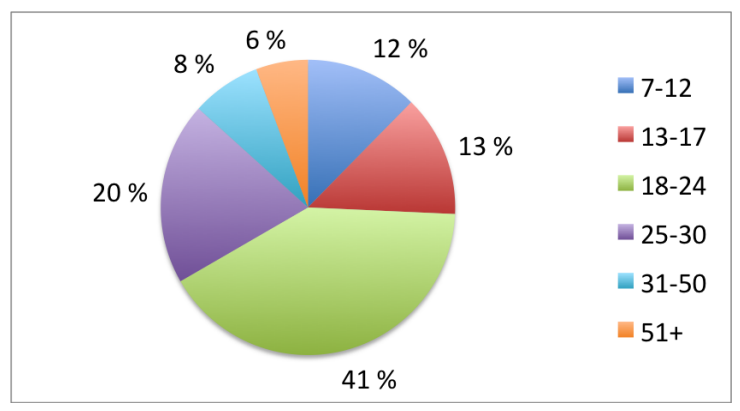

Fig. 3. Age distribution of respondents 
The largest group was the 18-24 years old (41\%), as a large portion of the respondents were students playing the game at the university campus. The age distributions of those who played the game and those who did not play the game is shown in Figure 4.

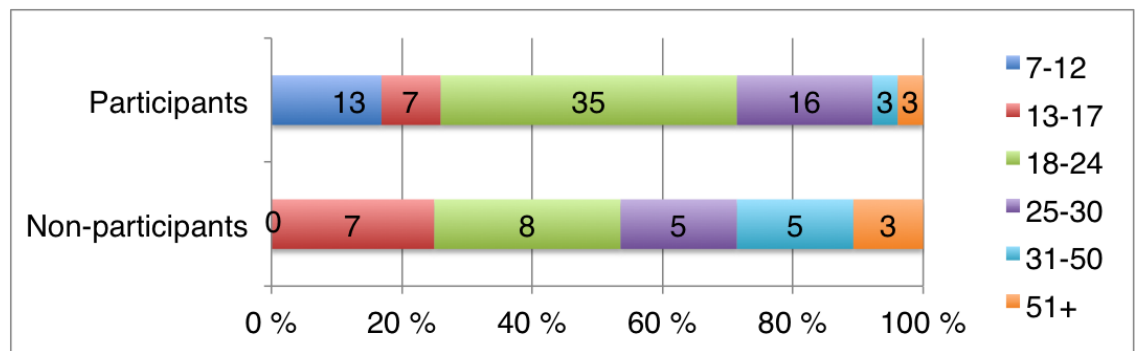

Fig. 4. Age distribution of those who played and those who did not

The first statement in the questionnaire focused on how comfortable the respondents were with being "thrown into" a game while passing by, without explicitly giving their consent to their silhouette being projected on the screen and suddenly being part of the game. Figure 5 shows the results where $84 \%$ of those who had played the game agreed or strongly agree that it was ok to be part of the game without consent on beforehand. The respondents not playing the game were more skeptic as only $52 \%$ agreed or strongly agreed to be comfortable becoming a part of the game without giving explicit consent.

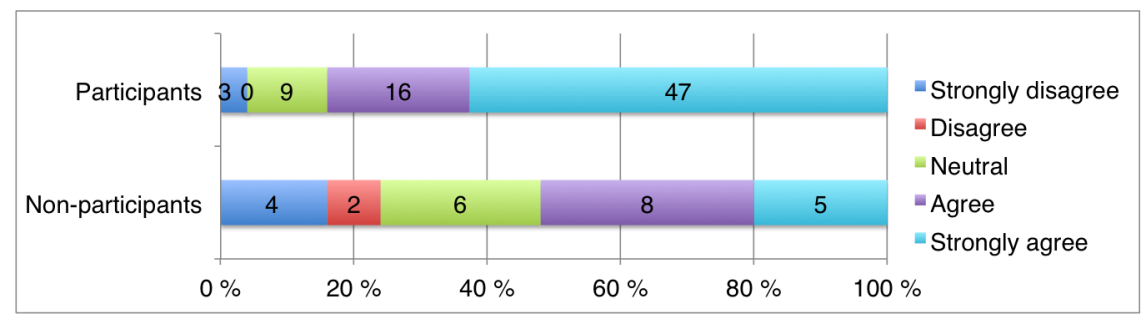

Fig. 5. Descriptive statistics on joining game without consent

The second statement in the questionnaire was about whether or not being comfortable with playing such a game in a public space (with many people around). The results from this statement are shown in Figure 6. Similar to statement one, respondents that played the game were much more positive to playing in public compared to those who did not play (79\% agree and strongly agreed for those who played vs. $46 \%$ for those who did not play). One striking result was that as little as $5 \%$ of those who played found it to be a problem to play in a public area with people around. 


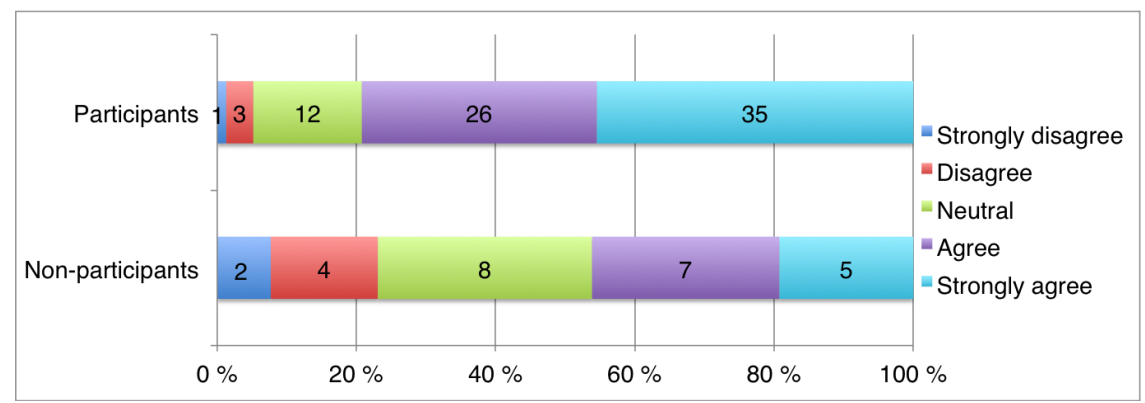

Fig. 6. Descriptive statistics on playing the game in public space

The third statement of the questionnaire focused on the immersion of the players by asking if they became unaware of their surroundings while playing the game. The results are shown in Figure 7, and give a clear indication that the game was immersive as much as $65 \%$ of those playing the game agreed or strongly agreed that they became unaware of their surroundings while playing. Also notice that as little as $13 \%$ of the players disagreed to this statement.

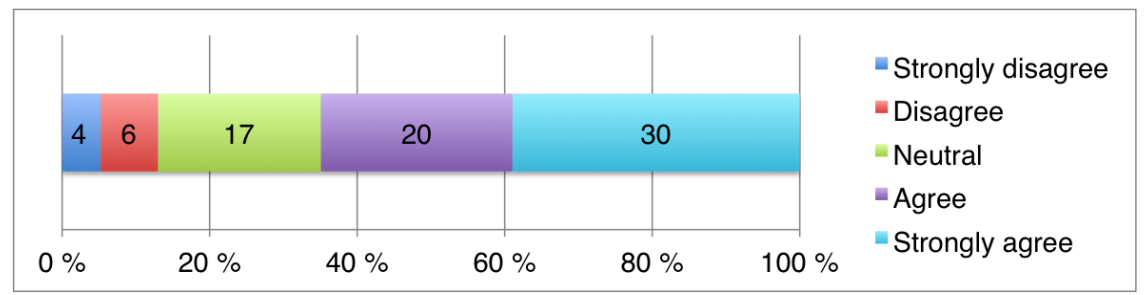

Fig. 7. Descriptive statistics on immersion

The fourth statement of the questionnaire consisted of two parts. First we asked whether they had played the game with other people or not. 56 out of 77 respondents (73\%) had played the multi-player mode. Part two of this statement asked if they thought it was more fun to play with someone, and the results are shown in Figure 8. The results clearly state that it was more fun to play with another person $(88 \%$ agreed or strongly agreed).

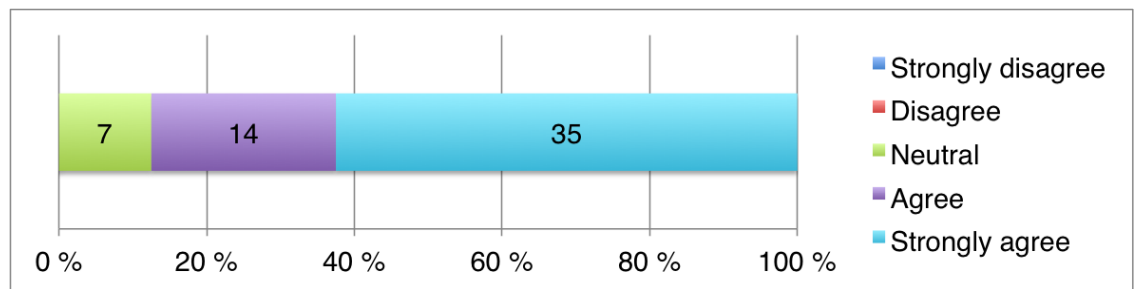

Fig. 8. Descriptive statistics on social enjoyment 
The fifth statements focused on whether or not it was ok to play with strangers. The results in Figure 9 show that about half of those who played the game $(51 \%)$ were ok playing with strangers, and $17 \%$ were negative.

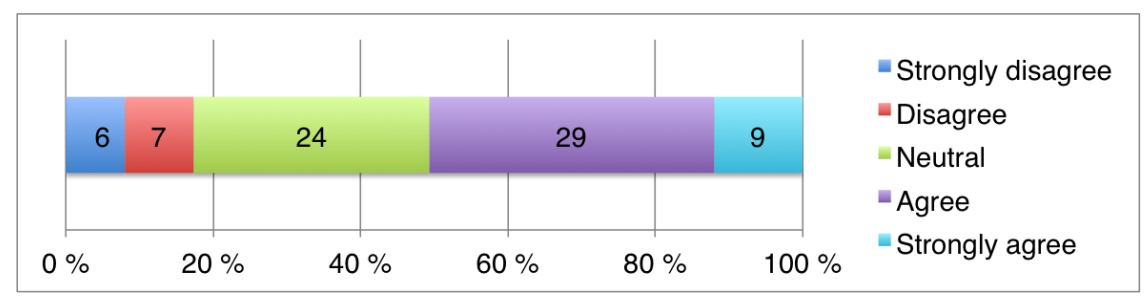

Fig. 9. Descriptive statistics on playing with strangers

The sixth statement of the questionnaire focused on whether the game caught the respondents' attention to a greater degree than a poster would have done. The results are shown in Figure 10. It is interesting to see the large difference between those who played the game and those who did not. $91 \%$ of those who played the game claimed that the game was more efficient in catching the audience attention compared to a poster. For those who did not play the game, $56 \%$ agreed. However, only $16 \%$ of the same group disagreed to this statement.

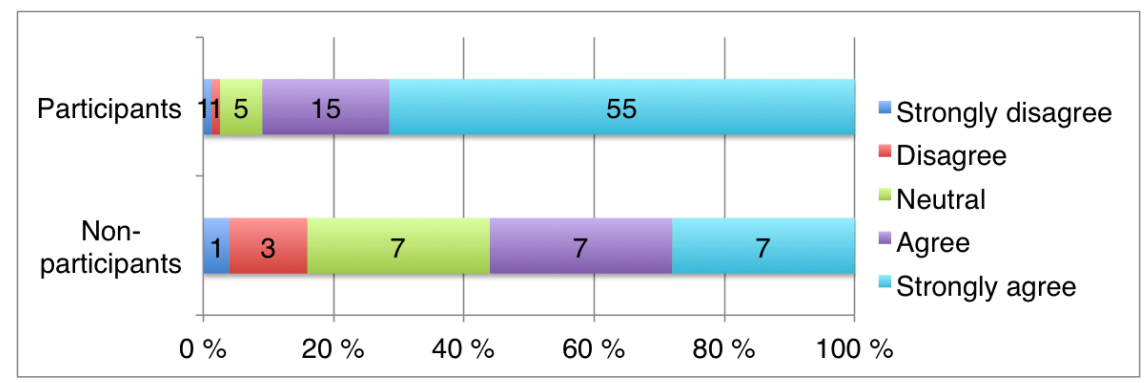

Fig. 10. Descriptive statistics on attention

The seventh statement of the questionnaire consisted of two parts where the first part asked whether the players had won the game or not. The winners of the game where then asked whether they were more likely to buy the advertised product after playing the game. The results in Figure 11 show that 33\% were more positive to buy the product after playing the game vs. $44 \%$ disagreed or strongly disagreed to the same statement. 


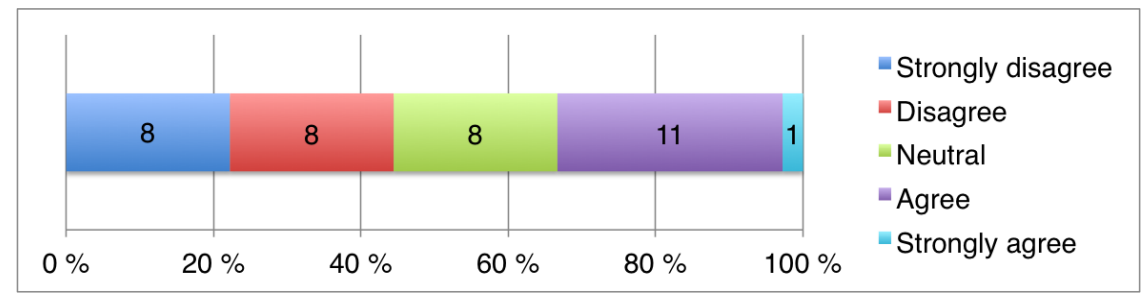

Fig. 11. Descriptive statistics on commercial effect

In the eight and final statement of the questionnaire, the respondents who played a version of game without advertisement for a specific product were asked if they would be comfortable participating in an corresponding advertising campaign. The results in Figure 12 show that $76 \%$ agreed or strongly agreed to participate in an interactive advertise campaign.

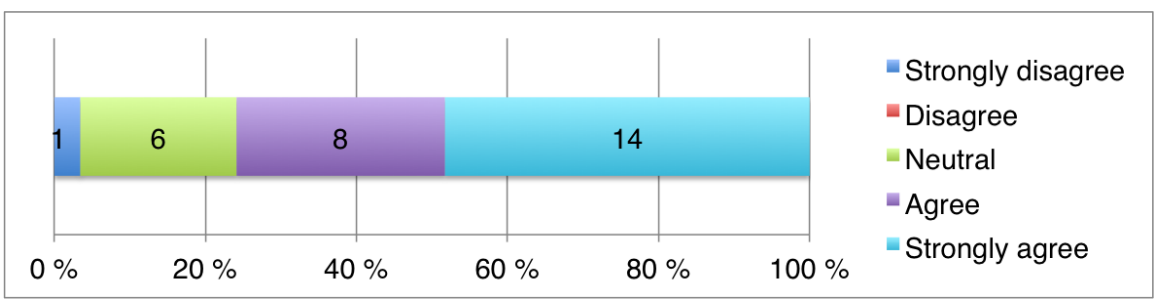

Fig. 12. Descriptive statistics on willingness to be part of campaign (29)

\section{Discussion}

One focus in our evaluation was to investigate how people felt about playing a motion-controlled game in a public space without giving explicit permission to participate. In our study the great majority (over $80 \%$ ) felt comfortable being part of a game without giving permission, and many expressed excitement about seeing themselves being represented on the screen. Some participants commented on feeling silly and being a bit embarrassed by playing in the public. However, the majority of the participants reported that they became unaware of their surroundings while playing, which contributed to making it less embarrassing. We also observed several teenage girls who felt it was embarrassing, but still wanted to play in order to win the gift certificate. There were also many who just passed by the installation without noticing the installation, which means that they did not move out of the passing-by phase as defined in the Audience Funnel by Müller [11]. However, once someone actually saw the game and reacted to it, they would often perform some subtle interaction like a wave or slowing down to look at their silhouette.

Another focus in the evaluation was to investigate what user groups were most active and engaged interacting with the installation. This can be affected by several factors, such as the type of application, the design of it, rewards, location/context of the installation, and comfort level of playing in public. As we expected, male users 
were more willing to stop and play at three of our test locations. However, at the shopping mall, the majority of players were girls and the same group of girls came back several times to play to try to win a gift certificate. At the university campus, we did not see any groups of only girls that would play, but girls in groups with boys would stop and interact. The age of the people playing the game varied depending on where the installation was placed. At the shopping mall and the waterpark where there was a wider variety of age among the people there, those who played the most and seemed to become most engaged where children and young teenagers.

For most of the tests, people did not play for a long time and the average playing time varied between 76 and 104 seconds. We suspect that the short playing times have to do with the fact that people in a public space are generally heading somewhere and have other plans than playing with an interactive campaign. These findings correspond to findings for the Magical Mirrors installation [12]. However, the playing time and the engagement increased when we announced the chance of winning a gift certificate. Results from the evaluation of the Magical Mirrors installation showed that $70 \%$ of those who had direct interaction with the installation did multiple interactions. We did not see similar results in our study, but we suspect that the Magical Mirrors' four displays in a row could can explain the difference. It was also possible to get people to revisit and play with our installation in our study by have a prize to win. Some groups of participants played several times in a row to increase their chances of winning a price.

Another focus in our study was group dynamics. As expected, passers-by who were in groups were much more likely to stop and play, and play for a longer time when stopping. People who were walking alone were much likely to pass over from the view and reacting and subtle interaction phases of the Audience Funnel to the direct interaction phase, while those who were in groups and discovered themselves on the screen very often interacted directly. Over $70 \%$ of the respondents to our questionnaire played together with others, and an overwhelming majority of them said that they thought the game was more fun because they played with someone else. Half of those who played alone said they would have played for a longer time if they had been playing with someone else. We also observed that those who played in groups seemed to be significantly less self-conscious while playing. Sometimes we observed that if one person in a group wanted to play, he or she would convince others to join because it would become less embarrassing.

\section{Conclusion}

In this article we have presented an evaluation of an interactive campaign using motion-controlled game technology along with a simple game concept of collecting falling balls into a container using body gestures. The first research question asked whether people are comfortable becoming a part of and playing a motion-controlled game in a public space without explicitly giving permission (RQ1). Our observations and results from the questionnaire shows that the large majority $(84 \%)$ of those who played the game think it was ok to join an interactive advertisement game without 
consent, while those who did not play were more skeptic (52\% thought it was ok). We also observed the same pattern regarding playing a game controlled by the user's body in public where $79 \%$ of those who played the game thought it was ok vs. $49 \%$ of those who did not. Further, few respondents stated that they were negative to join the game without consent and playing in public.

The second research question asked about which users were easiest to engage (RQ2), and the general answer is children and adolescents. However, for teenager and older, the engagement is very dependent on the number of people around, where the interactive campaign is located, and if the user is a part of a group or not.

The third research question asked whether people got engaged playing an interaction motion-controlled campaign or not (RQ3). As many as $65 \%$ of those who played the game agreed to become unaware of their surroundings while playing, and only $13 \%$ disagreed. This shows that if interactive motion-controlled campaigns are designed well immersion is not a problem.

The fourth research question asked about how the social aspects play a role when participating in an interactive motion-controlled campaign (RQ4). 88\% of those who played the game agreed that it was more fun to play the game as multi-player. From the observations we also noticed that it was easier for many to play together than alone, making it important to provide multi-player support for such interactive campaigns. Further, $51 \%$ of those who played agreed to that it was ok to play with strangers vs. $17 \%$ disagreeing.

The fifth and final research question asked about the effect of using motioncontrolled campaigns (RQ5). The statistics showed that $91 \%$ of they who played the game said that the interactive motion-controlled campaign had a better effect than a poster vs. $56 \%$ for those who did not play. Further that $33 \%$ of those who won the game were more positive to buying the product vs. $44 \%$ that disagreed to the same statement. For those who played a game without advertisement, $76 \%$ were positive to participate in an interactive advertisement similar to the game.

From the observations, we noticed that a major success factor getting high attendance and motivation for playing through the game is to provide prizes for the winners of the game. This is especially true for teenagers, youths and adults. Also we found that many playing the game did not play the game as designed, but just having fun with it without trying to win.

\section{References}

1. Petersen, N., Stricker, D.: Continuous natural user interface: Reducing the gap between real and digital world. In: ISMAR, pp. 23-26. (2009)

2. Juul, J.: A casual revolution: Reinventing video games and their players. The MIT Press (2012)

3. Norman, D.A.: Natural user interfaces are not natural. interactions 17, 6-10 (2010)

4. Nielsen, J.: Kinect Gestural UI: First Impressions. Jakob Nielsen's Alertbox (2010)

5. Strömberg, H., Väätänen, A., Räty, V.-P.: A group game played in interactive virtual space: design and evaluation. In: Proceedings of the 4th conference on Designing 
interactive systems: processes, practices, methods, and techniques, pp. 56-63. ACM, (2002)

6. Trifonova, A., Jaccheri, L., Bergaust, K.: Software engineering issues in interactive installation art. International Journal of Arts and Technology 1, 43-65 (2008)

7. Satomi, M., Sommerer, C.: game_of life: interactive art installation using eyetracking interface. In: Proceedings of the international conference on Advances in computer entertainment technology, pp. 246-247. ACM, (2007)

8. Costello, B., Muller, L., Amitani, S., Edmonds, E.: Understanding the experience of interactive art: Iamascope in Beta_space. In: Proceedings of the second Australasian conference on Interactive entertainment, pp. 49-56. Creativity \& Cognition Studios Press, (2005)

9. José, R., Cardoso, J.C.: Opportunities and challenges of interactive public displays as an advertising medium. Pervasive Advertising, pp. 139-157. Springer (2011)

10. Brignull, H., Rogers, Y.: Enticing people to interact with large public displays in public spaces. In: Proceedings of INTERACT, pp. 17-24. (2003)

11. Michelis, D., Müller, J.: The audience funnel: Observations of gesture based interaction with multiple large displays in a city center. Intl. Journal of HumanComputer Interaction 27, 562-579 (2011)

12. Müller, J., Alt, F., Michelis, D., Schmidt, A.: Requirements and design space for interactive public displays. In: Proceedings of the international conference on Multimedia, pp. 1285-1294. ACM, (2010)

13. Malone, T.W.: Toward a theory of intrinsically motivating instruction*. Cognitive science 5, 333-369 (1981)

14. Michelis, D.: Interaktive Großbildschirme im öffentlichen Raum. Springer (2009)

15. Peltonen, P., Kurvinen, E., Salovaara, A., Jacucci, G., Ilmonen, T., Evans, J., Oulasvirta, A., Saarikko, P.: It's Mine, Don't Touch!: interactions at a large multitouch display in a city centre. In: Proceedings of the SIGCHI Conference on Human Factors in Computing Systems, pp. 1285-1294. ACM, (2008)

16. Russell, D.M., Trimble, J.P., Dieberger, A.: The use patterns of large, interactive display surfaces: Case studies of media design and use for BlueBoard and MERBoard. In: System Sciences, 2004. Proceedings of the 37th Annual Hawaii International Conference on, pp. 10 pp. IEEE, (2004)

17. Wang, A.I., Føllesdal, E.A.: Evaluation of a Social Multiplayer Game Featuring Multimodal Interaction. In Proceedings of the IASTED International Conference on Software Engineering and Applications (SEA 2010), (2010)

18. Wired Magazine, Augmented Reality: Kinect Fitting-Room for Topshop, Moscow. Web: http://www.wired.com/2011/05/augmented-reality-kinect-fitting-roomfor-topshop-moscow/, (2011)

19. Basili, V.R.: Software modeling and measurement: the Goal/Question/Metric paradigm. University of Maryland for Advanced Computer Studies (1992)

20. Wohlin, C., Runeson, P., Höst, M., Ohlsson, M.C., Regnell, B., Wesslén, A.: Experimentation in software engineering. Springer (2012)

21. Asplem, M.H., Aasbakken, M.: Evaluation of an Interactive Campaign, Exploring the use of a motion-controlled game in a public space. Master Thesis, Norwegian University of Science and Technology (2012) 